TITLE: PHYSIOLOGICAL DEMAND AND PACING STRATEGY DURING THE NEW COMBINED EVENT IN ELITE PENTATHLETES

AUTHORS: YANN LE MEUR ${ }^{1}$, SYLVAIN DOREL ${ }^{1,2}$, YANN BAUP ${ }^{1}$, JEAN PIERRE, GUYOMARCH $^{3}$, CHRISTIAN ROUDAUT $^{3}$, CHRISTOPHE HAUSSWIRTH $^{1 *}$

${ }^{1}$ Research Department, National Institute of Sport, Expertise and Performance, 75012 Paris, FRANCE.

${ }^{2}$ University of Nantes, Laboratory "Motricité, Interactions, Performance” (EA 4334), Nantes, F-44000 FRANCE.

${ }^{3}$ Modern Pentathlon French Federation, 75640 Paris, FRANCE.

\title{
*Corresponding Author :
}

Dr Christophe Hausswirth, PhD

Research Department,

National Institute of the Sport and Physical Education (INSEP),

11 Avenue du Tremblay, 75012 Paris, FRANCE

Phone : + 33 1-41-74-43-85

Fax : + 33 1-41-74-45-35

E-mail : christophe.hausswirth@insep.fr

Running title : Combined event's physiology in pentathlon

Article publié dans :

Eur J Appl Physiol. 2012 Jul;112(7):2583-93. doi: 10.1007/s00421-011-2235-2. 


\begin{abstract}
1 ABSTRACT
2 Purpose: To evaluate the physiological demands and effects of different pacing strategies on

3 performance during the new combined event (CE) of the modern pentathlon (consisting of three pistol

4 shooting sessions interspersed by three 1-km running legs).

5 Methods: Nine elite pentathletes_realised five tests: a free-paced CE during an international

6 competition; an incremental running test to determine $\dot{\mathrm{V}} \mathrm{O}_{2 \max }$ and its related velocity $\left(\mathrm{v} \dot{\mathrm{V}} \mathrm{O}_{2 \max }\right.$ ) and

7 three experimental time-trial $\mathrm{CE}$, where the pacing strategy was manipulated $\left(\mathrm{CE}_{\text {ref }}, \mathrm{CE}_{100 \%}, \mathrm{CE}_{105 \%}\right)$.

$8 \mathrm{CE}_{\text {ref }}$ reproduced the international competition strategy with a $170 \mathrm{~m}$ fast running start within the first 2

kilometres. $\underline{\mathrm{CE}_{100 \%}}$ and $\mathrm{CE}_{105 \%}$ imposed a constant strategy over km-1 and km-2 with a velocity of

$100 \%$ and $105 \%$ of the mean speed adopted over the same sections during the international

competition, respectively. Km-3 was always self-paced.
\end{abstract}

12 Results: The subjects ran $\mathrm{CE}_{\text {ref }}$ at $99 \pm 4 \%$ of $\vee \dot{V}_{2 \max }$ and reached $100 \pm 5 \%, 100 \pm 7 \%, 99 \pm 8 \%$ of

$13 \dot{\mathrm{V}} \mathrm{O}_{2 \max }$ at the end of kilometres 1,2 , and 3, respectively $\left(\dot{\mathrm{V}} \mathrm{O}_{2 \max }: 72 \pm 6 \mathrm{mlO}_{2} \cdot \mathrm{min}^{-1} \cdot \mathrm{kg}^{-1}\right)$, with a peak 14 blood lactate concentration of $13.6 \pm 1.5 \mathrm{mmol} . \mathrm{L}^{-1}$. No significant differences in overall performance 15 were found between the pacing conditions $\left(753 \pm 30 \mathrm{~s}, 770 \pm 39 \mathrm{~s}, 768 \pm 27 \mathrm{~s}\right.$ for $\mathrm{CE}_{\mathrm{ref}}, \mathrm{CE}_{100 \%}$ and $\mathrm{CE}_{105 \%}$, 16 respectively, $\mathrm{p}=0.63$ ), but all of the shooting performance parameters were only stable in $\mathrm{CE}_{\text {ref }}$.

17 Conclusion: Completion of CE by elite pentathletes elicits a maximal aerobic contribution coupled 18 with a high glycolytic supply. Manipulating the mean running speed over km-1 and km-2 had strong influence on the overall pacing strategy and induced minor differences in shooting performance but it 20 didn`t affect overall performance.

22 Keywords: Energetics, Running, Shooting, Olympic discipline 


\section{1}

2 Paragraph 1 The modern pentathlon has been an Olympic multidisciplinary sport since 1912. It 3 consists of pistol shooting, fencing, swimming, horse riding events and a 3-km run, all of which are completed in a single day with a recovery period of approximately 1 hour between each event. In 2009, the "Union Internationale de Pentathlon Moderne" (UIPM) changed the format of the competition, and decided that the running and shooting disciplines would be carried out in tandem. Specifically, pentathletes will begin the final event with a handicap, and complete three bouts of shooting, with each bout followed by a $1000 \mathrm{~m}$ run. In each of the three rounds of firing, athletes must shoot down 5 targets before they begin running. If after 70 seconds, one or more of the five targets has not been hit, the pentathlete can start running the next leg without being further penalized. Considering that the differences between the top half competitors is usually less than 30 seconds at the beginning of the combined event (UIPM database), it is of considerable value for the pentathletes to understand how they can excel in this new discipline, especially in light of the fact that it will be newly introduced during the 2012 London Olympic Games.

Paragraph 2 There are currently no scientific reports that have evaluated the physiological demand of the new combined event. An understanding of the metabolic requirements needed to successfully complete this event would allow the intensity level for this new combined event to be characterized, and allow elite pentathletes to optimize their training programs. In addition, the ability to combine running and shooting in an optimal manner has been proposed as an important determinant of success. Thus, some authors have suggested that pacing strategies may also deserve particular attention (Le Meur et al. 2010). A recent study conducted during a World cup competition (Le Meur et al. 2010) reported that top pentathletes adopt a_global "negative pacing strategy" (i.e. negative-split) (Abbiss and Laursen 2008), whereby their speed increases during the last kilometre of the combined event. This tactic may be associated with the assumption that a lower running velocity before the shooting event may result in a better shooting performance by reducing the possible effects of fatigue that are associated with a higher running intensity, as suggested by Le Meur et al. (2010) for elite pentathletes and Hoffman et al. (1992) for elite biathletes. 
Paragraph $\underline{3}$ Le Meur et al. (2010) showed also that pentathletes adopt a "positive pacing strategy" (i.e. positive split) within each $1000 \mathrm{~m}$ run, whereby after peak speed is reached over the first $200 \mathrm{~m}$, competitors progressively slow down. However, the benefit of this strategy still remains unclear considering the heterogeneous results reported in the literature. On one hand, several studies showed that a fast start (ranging between 2 and $5 \%$ of the mean running speed over the first 10-25\% of the race distance) is detrimental in some prolonged locomotive events lasting between 2 and 30 minutes, such as running (Billat et al. 2001b), swimming (Thompson et al. 2003), cycling (Wilberg and Pratt 1988), and triathlon (Hausswirth et al. 2010). On the other hand, two recent studies reported that a fast start could also improve performance during 3- and 5-min cycling exercises by speeding $\mathrm{V}_{2}$ kinetics (Aisbett et al. 2009; Bailey et al. 2011; Bishop et al. 2002). In the particular context of modern pentathlon, Le Meur et al. (2010) hypothesized that the fast start systematically observed within each running kilometre in competition may be related to i) the design of the new shooting-running combined event, which could perturb the determination of an "optimal" initial running velocity over each kilometre by inducing frequent variations in running velocity during the event or more positively to (ii) a potential recovery associated with each shooting session; iii) a strategy to reduce the deleterious effects of running on the subsequent shooting performance. Nevertheless, each of these theories are merely hypothetical as there are currently no studies that have investigated which optimal pacing strategy will lead to the best equilibrium between fatigue within each running leg, and maximal mean running speed, shooting performance, and hence, global performance during the combined event. In this perspective, determining the effect of different pacing strategies on shooting and overall run-shoot performance would be particularly informative, considering that studies on the multidisciplinary sports, which share similarities with the combined event (e.g. Nordic biathlon) are scarce (Hoffman et al. 1992).

Paragraph $\underline{4}$ The first objective of this research was to describe the physiological demands associated with the new combined shooting-running event performed by elite pentathletes (Part 1). The second purpose was to investigate the influence of different pacing strategies on running, shooting, and global performance, and to describe the concomitant physiological response. To this end, we compared three 
1 conditions for which the speed during the first two $1000 \mathrm{~m}$ legs were differentially controlled: i) a condition reproducing the competition strategy with a fast start for the first $\sim 200 \mathrm{~m}\left(\mathrm{CE}_{\mathrm{ref}}\right)$, ii) a mean constant speed equivalent to $\mathrm{CE}_{\text {ref }}\left(\mathrm{CE}_{100 \%}\right)$, and iii) a higher mean constant speed $\left(\mathrm{CE}_{105 \%}\right)$. We

4 hypothesized that $\mathrm{CE}_{100 \%}$ strategy would be less physically stressful by decreasing the accumulation of 5 fatigue related metabolites and may enhance the mean running speed when compared with $\mathrm{CE}_{\text {ref }}$

6 without affecting shooting performance (i.e. Part 2: effect of a fast start strategy within the two first kilometres on performance parameters). Considering that pentathletes are able to increase their speed 8 over the last running leg in competition (Le Meur et al. 2010), we also hypothesized that $\mathrm{CE}_{105 \%}$ would 9 allow the elite pentathletes to gain substantial time over the two first running legs, what would improve both global running and overall performances, when compared with $\mathrm{CE}_{\text {ref }}$ and $\mathrm{CE}_{100 \% \text { (i.e. }}$ Part 3: effect of the mean running speed over the two first kilometres on performance parameters).

\section{MATERIALS AND METHODS}

\section{Participants}

Paragraph 5 Nine international-level male $(n=8)$ and female $(n=1)$ pentathletes from the French junior and senior modern pentathlon teams were studied. They gave their written informed consent to participate in this investigation, which was conducted according to the Declaration of Helsinki. A local ethics committee for the protection of individuals gave approval concerning the project before its initiation. All the participants were currently engaged in international competitions (World Cup events, European and World Championships) and four of them were medallists during the 2010 World Championships. Their characteristics are presented in Table 1. During the entire experimental procedure, the subjects did not perform any exhausting exercise in the 48 hours preceding each test. A schematic representation of the experimental protocol is provided in Fig. 1.

\section{Competition testing}


1 Paragraph 6 Prior to the experiment, data were collected during an international Modern Pentathlon

2 competition organized in Paris, specifically at the French National Institute of Sport, Expertise and

3 Performance (France). The combined event was conducted over a 3060-m distance performed on a

$4 \quad 340-\mathrm{m}$ indoor running track covered three times during each running leg (3 track laps $\mathrm{x} 3$ running

5 periods, inside air temperature of $18^{\circ} \mathrm{C}$ ). Each of the three legs comprised a 20 -m length firing-area

6 and a 1000 m run section.

7 Paragraph 7 A video acquisition system recording at a frequency of $25 \mathrm{~Hz}$ (Sony HDR-CX12 8 AVHD) was posted around the track. It included three digital cameras located 1) at the exit of the 9 shooting range (i.e. start of running: 0-m), 2) at 170-m and 3) on the finish line. Running speed (in $10 \mathrm{~km} \cdot \mathrm{h}^{-1}$ ) was calculated via a subsequent video analysis (Pro suite version 5.0, Dartfish ${ }^{\circledR}$, Fribourg, 11 Swiss) over the following sections: 0-170m, 170-340m, 340-510m, 510-680m, 680-850m, 850-1000m.

\section{Maximal running test}

Paragraph 8 One week after the competition, the subjects underwent a maximal incremental running test to determine their maximal oxygen uptake $\left(\dot{\mathrm{V}} \mathrm{O}_{2 \max }\right)$ and the velocity at which $\dot{\mathrm{V}} \mathrm{O}_{2 \max }$ occurred ( $\left(\mathrm{v} \mathrm{V}_{2 \max }\right.$ ) on the same $340-\mathrm{m}$ indoor track. The test began at $12 \mathrm{~km} \cdot \mathrm{h}^{-1}$ and the speed was increased by $1 \mathrm{~km} \cdot \mathrm{h}^{-1}$ every $3 \mathrm{~min}$ until volitional exhaustion. An auditive signal each $20 \mathrm{~m}$ indicated precisely the speed the subject had to keep over. Between each increment, blood samples were taken from the participants ear lobes during a 1-min rest period and analyzed using a Lactate Pro system (2000). 20 Oxygen uptake $\left(\dot{\mathrm{V}}_{2}\right)$ and expiratory flow $\left(\dot{\mathrm{V}}_{\mathrm{E}}\right)$ were recorded breath by breath with a telemetric system collecting gas exchanges (Cosmed $\mathrm{K} 4 \mathrm{~b}^{2}$, Rome, Italy), which was calibrated before each test according to the manufacturer recommendations. Heart rate values (HR) were monitored every second using a Polar unit (RS800sd, Polar Electro, Kempele, Finland). Expired gases and HR values were subsequently averaged every $5 \mathrm{~s}$. $\dot{\mathrm{V}} \mathrm{O}_{2 \max }$ was determined according to criteria described by Howley et al. (1995) - that is, a plateau in $\dot{\mathrm{V}}_{2}$ despite an increase in running speed, a respiratory exchange ratio 
1 value of 1.15 and a HR value over $90 \%$ of the predicted maximal value. The lactate threshold (LT) was assessed according to the D-max method previously described by Cheng et al. (1992).

3

\section{Experimental combined events}

5

\section{Analysis of the combined event performed during the international competition}

Paragraph 9 The video analysis performed during the competition testing revealed that the mean running speeds over the first 2 kilometres were not significantly different from each other. Based on this report, the mean running speed adopted over the two first $1 \mathrm{~km}$ was calculated for each subject and considered as the reference speed value (v2000ref). The speed value on the first $170 \mathrm{~m}$ was significantly higher than the mean running speed over each respective kilometre $(+11.8 \pm 5.8 \%,+9.8$ $\pm 3.3 \%$ and $+10.1 \pm 4.4 \%$ for km-1, km-2 and km-3, respectively, $p<0.001)$. Except the first $170 \mathrm{~m}$ segment, no significant difference in running speed were observed between the 5 subsequent sections of each running leg $(p>0.05)$.

\section{The three pacing conditions in running}

Paragraph 10 Analysis of the running speed variations during the international competition allowed the determination of three different pacing strategies, which were performed in a randomised order. The training program was maintained similar throughout the total period of experiments. These three sessions were conducted in the official competition format: $20-\mathrm{m}$ run followed by three shootingrunning sessions, in total shooting 15 targets and running 3-km. During each experimental combined event, the running speed was manipulated only during the two first kilometres of the experimental combined events (Fig. 1), in order to evaluate the effect of the pacing strategy over these sections on i) running performance during $\mathrm{km}-3$, ii) shooting performance parameters and iii) overall performance. An auditive signal each $20 \mathrm{~m}$ indicated precisely the speed the subject had to keep over and a welltrained experienced runner ran at their side over these sections to help them to adjust their speed to the targeted one. The pentathletes were always instructed to complete the entire last kilometer (i.e. $\mathrm{km}-3$ ) as fast as possible to maximize performance. The pacing strategy over this section was let free. All 
1

experiments (Fig. 1) were carried out on the same indoor track employed for the international

\section{$7 \quad$ Running sessions.} 8 Paragraph 11 Reference strategy $\left(\mathrm{CE}_{\mathrm{ref}}\right)$. This condition was a simulation of the fast start strategy 9 adopted by the pentathletes during the international competition. Subjects had to adopt a running 10 competition and the maximal incremental running test (inside air temperatures ranging from $18^{\circ}$ to $\underline{\left.20^{\circ} \mathrm{C}\right) \text {. Before each combined event, pentathletes were required to perform a warm-up session }}$ comprising 20 min at $60 \%$ v $\underline{\underline{\mathrm{V}}} \underline{\mathrm{O}}_{2 \max }$ and $4-6$ sprints over 30 to 60 -m interspersed by $30 \mathrm{~s}$ of passive recovery. speed $10 \%$ higher than v2000ref over the first $170-\mathrm{m}$ of each of the two first running sections. Then, the running speed was adjusted to $98 \%$ of v2000ref over the last $830-\mathrm{m}$ of each of these two first kilometres. Thus, the average running speed imposed over km-1 and km-2 was equal to v2000ref.

Paragraph 12 Constant strategies $\left(\mathrm{CE}_{100 \%}, \mathrm{CE}_{105 \%}\right)$. The two other conditions imposed a constant pace over the two first kilometres. In the $\mathrm{CE}_{100 \%}$ condition, the pentathletes were instructed to maintain a running speed corresponding to $100 \%$ of v2000ref over $\mathrm{km}-1$ and $\mathrm{km}-2$. In the other condition $\left(\mathrm{CE}_{105 \%}\right)$, the running speed was imposed at $105 \%$ of v2000ref over the same sections.

Paragraph 13 Mean running speed (in $\mathrm{km} \cdot \mathrm{h}^{-1}$ ) was calculated via a subsequent video analysis for $\mathrm{km}-$ 1 and $\mathrm{km}-2$, using the same methodology employed during the international competition. For the last kilometre (free-paced), the running speed was calculated over the following sections: 0-340m, 340680m, 680-1000m.

Paragraph 14 Before each combined event, the pentathletes were equipped with the same portable gas

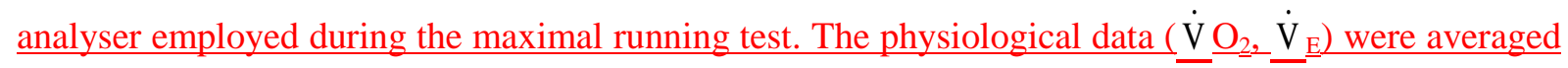
every $5 \mathrm{~s}$ from the breath-by-breath values. Heart rate values (HR) were monitored every second using a Polar unit (RS800sd, Polar Electro, Kempele, Finland). All the data were analysed (i.e. mean value) on time periods corresponded to the last $30 \mathrm{~s}$ of run sections and each shooting session. Blood samples 
blood lactate concentration ( $\left[\mathrm{La}^{-}\right]_{\mathrm{b}}$ ) decreased, using the same portable blood analyser employed

\section{Shooting sessions.}

5 Paragraph 15 The spatial organisation employed during the competition was reproduced during the 6 simulated combined events. The three shooting rounds (i.e. standing position) were undertaken on a 7 firing area with an individual shooting box. Electronic targets (EasyTargets ${ }^{\circledR}$, Competition Level A, 8 Easypenta, France) were composed by one black single aim and 5 green/red lamps to indicate the 9 number of remaining successful shots. The competitors were required to hit 5 times the single target of $250 \mathrm{~mm}$ diameter within a $59.5 \mathrm{~mm}$ diameter. Targets were situated at $10 \mathrm{~m}$ from the firing line. The shooting position was left free but the pentathletes were asked to hold the pistol with only one hand, according to UIPM rules. Each pentathlete used his/her own pistol, which was deposited in his box after each shooting session. The latter had to be placed on the table pointing targets, unloaded in an open position.

Paragraph 16 Targets were equipped with a sensing receptor, which was activated when pentathletes succeeded in hitting the target (Scatt USB, Scatt ${ }^{\odot}$, Moscow, Russia). The trigger of each pistol was similarly connected to an electronic pressure-sensitive system, which was activated at each shot (Scatt USB, Scatt ${ }^{\odot}$, Moscow, Russia) with a sampling rate of $100 \mathrm{~Hz}$. Records from the digital targets were used to measure the shooting accuracy (i.e. rate of success in hitting the five targets during each shooting session as a percentage), the shooting time (i.e. the global delay between the first and the last shot of the three shooting sessions) and the shooting delay per attempt (i.e. the mean period of time between two consecutive shots). The transition time on the shooting range was also calculated by deducting the shooting time from the time spent on the shooting range. All the variables were considered for each running lap or each shooting session individually and also pooled for the entire race. Because the first shooting session preceded the first running section, where the pacing strategy 
1 was manipulated, the shooting data presented in the manuscript will distinguish the results for the

2 whole event and only for the shooting sessions 2 and 3.

3

\section{$4 \quad$ Statistical analyses}

5 Paragraph 17 Statistical analysis was performed using the SPSS 19 package (IBM corporation, Inc.

6 New York, USA). All variables were expressed as mean and standard deviation (Mean \pm SD). The

7 level of significance was set at $p<0.05$. We assessed the distribution of the analysed variables using a

8 Shapiro-Wilk test. For overall performance, running performance, transition time and physiological

9 parameters, the results showed that the distributions respected a normal distribution. Then, a two-way analysis of variance (pacing strategy $\mathrm{x}$ running section) for repeated measures was performed to analyse the effects of the running section and the pacing strategy on running speed, $\mathrm{HR}, \dot{\mathrm{V}} \mathrm{O}_{2}$ and $\dot{\mathrm{V}}_{\mathrm{E}}$ values as dependent variables. A Tukey post hoc test was used to determine differences among all pacing strategies and periods during exercise. A pair t-test was performed to compare overall performance between the international competition and $\mathrm{CE}_{\text {ref. }}$ For the shooting parameters (shooting time, shooting accuracy and delay per shot), the distributions deviated from normal distribution, so a non parametric Friedman's rank test was undertaken to assess the statistical differences between conditions for each shooting session (S1, S2, S3) and to evaluate the statistical differences in time for each pacing strategy. When a significant F-value in Friedman's analysis was found, a post hoc test was used to determine the between-means differences. Effect size [standardized difference or Cohen's d (Cohen 1988)] was also used, where appropriate, to evaluate differences. Thresholds for small, moderate, and large effects were 0.20, 0.50, and 0.80, respectively (Cohen 1988).

\section{RESULTS}

Paragraph 18 All pentathletes completed the protocol and succeeded to conform the pacing strategies imposed over the two first kilometres at $\pm 0.2 \mathrm{~km} \cdot \mathrm{h}^{-1}$. Table 2 depicts the results concerning performance for the three combined event conditions. No significant difference on overall 
1 performance was observed between $\mathrm{CE}_{\text {ref }}$ and the international competition $(p=0.38)$. The same result

2 was observed when considering the three experimental conditions $(p=0.63)$, even when the first

3 shooting session was excluded from the analysis $(p=0.53)$.

5

6

7

8

9

Paragraph 19 Running performance. Figure 2 (panel A) presents the evolution of the mean running speed during the three conditions. The statistical analysis indicated a significant interaction effect (pacing condition $\mathrm{x}$ running section) on running performance $(p<0.001)$.

Paragraph 20 Time period effect. No significant difference in running speed were reported between $\mathrm{km}-1$ and km-2 for $\mathrm{CE}_{\text {ref }}(p=0.39), \mathrm{CE}_{100 \%}(p=0.93)$ and $\mathrm{CE}_{105 \%}(p=0.15)$. A significant increase in running speed was observed in $\mathrm{km}-3$ for both $\mathrm{CE}_{\text {ref }}(p=0.003)$ and $\mathrm{CE}_{100 \%}(p<0.001$, effect size $=$ 0.75). The last kilometre was run slower than km-2 in $\mathrm{CE}_{105 \%}(p<0.001$, effect size $=2.22)$. The running speed was significantly lower over the section $[340-680 \mathrm{~m}]$ than over the sections $[0-340 \mathrm{~m}]$ and $[680-1000 \mathrm{~m}]$, for the three conditions $(p<0.01)$. While the running speed was lower over $[680-$ $\underline{1000 \mathrm{~m}]}$ than over $[0-340 \mathrm{~m}]$ in $\mathrm{CE}_{105 \%}(p<0.05)$, no significant difference was reported in the two other conditions, when comparing these two sections of $\mathrm{km}-3$ in $\mathrm{CE}_{\text {ref }}$ and $\mathrm{CE}_{100 \%}$.

Paragraph 21 Pacing strategy effect. Non-significant difference in total running time and mean running over the $3-\mathrm{km}$ were observed between the three conditions $(p=0.81$, Table 2$)$. There was a systematic significant difference in running speed over the first $2 \mathrm{~km}$ in relation to the starting strategy when comparing $\mathrm{CE}_{105 \%}$ with $\mathrm{CE}_{\text {ref }}(p=0.02$ and $p=0.05$ for $\mathrm{km}-1$ and $\mathrm{km}-2$, respectively) and $\mathrm{CE}_{100 \%}$ ( $p<0.001$ and $p=0.05$ for $\mathrm{km}-1$ and $\mathrm{km}-2$, respectively). The running speed over $\mathrm{km}-3$ was lower in $\mathrm{CE}_{105 \%}$ than in $\mathrm{CE}_{\text {ref }}(p<0.001$, effect size $=1.33)$ and in $\mathrm{CE}_{100 \%}(p<0.001$, effect size $=$ 1.77). The running speed was significantly lower over each sections of $\mathrm{km}-3$ in $\mathrm{CE}_{105 \%}$ than in $\mathrm{CE}_{\mathrm{ref}}$ and $\mathrm{CE}_{100 \%}(p<0.001)$, while no significant difference was reported between $\mathrm{CE}_{\mathrm{ref}}$ and $\mathrm{CE}_{100 \%}$ :

Paragraph 22 Shooting performance. Figure 2 (panel B-D) describes the evolution of the shooting performance parameters throughout the three sessions and for each of the three conditions.

Paragraph 23 Time period effect. No significant difference was observed between the three shooting sessions for $\mathrm{CE}_{\text {ref, }}$, when considering the shooting time $(p=0.20)$, the shooting accuracy $(p=0.25)$ and 
1 the delay per shot between the three shooting sessions (Friedman ANOVA, $p=0.06$ ). During $\mathrm{CE}_{100 \%}$,

2 no significant difference was observed between the three sessions for the shooting time $(p=0.24)$ and

3 the shooting accuracy $(p=0.85)$. A significant increase in delay per shot was observed when 4 comparing S1 and S3 $(p=0.03$, effect size $=0.61)$. During $\mathrm{CE}_{105 \%}$, the shooting time increased during 5 S3 $(p=0.01$, effect size $=0.91)$ because of a non significant tendency of the shooting accuracy to 6 decrease $(p=0.07)$ and a significant increase of the delay per shot $(p=0.03$, effect size $=0.76)$.

7 Paragraph 24 Pacing strategy effect. No significant difference was observed between the three 8 conditions when comparing shooting time for the whole combined event $(p=0.65)$, even when 9 excluding the first shooting session $(p=1.00)$. A similar result was observed by considering each shooting session individually ( $p=0.96, p=0.27, p=0.37$ for S1, S2, S3, respectively). Shooting accuracy values were not significantly different between the three conditions when considering the whole combined event $(p=0.95)$, S2 and S3 together $(p=0.87)$, and each shooting session individually ( $p=0.60, p=0.52, p=0.47$, for $\mathrm{S} 1, \mathrm{~S} 2, \mathrm{~S} 3$, respectively). A similar result was reported concerning the delay per shot for whole combined event $(p=0.60)$, the two last shooting sessions $(p=$ 0.85 ) and each session individually ( $p=0.70, p=0.46, p=0.90$, for S1, S2, S3, respectively).

Paragraph 25 Transition time. No significant difference in the transition time was observed between the three conditions $\left(29 \pm 6 \mathrm{~s}, 30 \pm 5 \mathrm{~s}\right.$ and $32 \pm 5 \mathrm{~s}$, for $\mathrm{CE}_{\mathrm{ref}}, \mathrm{CE}_{100 \%}$ and $\mathrm{CE}_{105 \%}$, respectively, $p=$ $0.44)$.

Paragraph 26 Physiological parameters. Table 3 indicates mean values for $\mathrm{HR}, \dot{\mathrm{V}} \mathrm{O}_{2}, \dot{\mathrm{V}}_{\mathrm{E}}$ and blood lactate accumulation for the running bouts. $\mathrm{CE}_{\text {ref }}$ was performed at $100 \pm 5 \% \quad \dot{\mathrm{V}} \mathrm{O}_{2 \max }, 99 \pm 4.3 \%$ $\mathrm{v} \dot{\mathrm{V}} \mathrm{O}_{2 \max }$ and $96 \pm 3 \% \mathrm{HR}_{\max }$ (Fig. 3). The statistical analysis indicated a significant interaction effect (period time $\mathrm{x}$ pacing strategy) on $\mathrm{HR}(p=0.02)$ and $\dot{\mathrm{V}}_{\mathrm{E}}$ values $(p=0.02)$, but no effect on $\dot{\mathrm{V}} \mathrm{O}_{2}$ values $(p=0.13)$.

Paragraph 27 Time period effect. A significant increase in $\mathrm{HR}$ values was observed for both $\mathrm{CE}_{\text {ref }}$ after km-1 $(p<0.001$, effect size $=1.33)$ and after km-2 $(p<0.001$, effect size $=1.90)$. Similar results 
1 were reported for $\mathrm{CE}_{100 \%}(p<0.001$, effect size $=2.36)$. A significant difference was reported for

$2 \mathrm{CE}_{105 \%}$ between km-1 and km-2 $(p=0.02$, effect size $=2.32)$, but not between km-2 and km-3 $(p=$

$30.25) . \dot{\mathrm{V}}_{\mathrm{E}}$ values increased throughout the combined event for $\mathrm{CE}_{\mathrm{ref}}(p<0.01)$ and $\mathrm{CE}_{100 \%}(p<0.05)$

4 with large effect sizes (>1.0). During $\mathrm{CE}_{105 \%}, \dot{\mathrm{V}}_{\mathrm{E}}$ values increased only after the first kilometre $(p<$ $5 \quad 0.01$, effect size $=1.29)$.

6 Paragraph 28 Pacing strategy effect. HR values were significantly lower in $\mathrm{CE}_{105 \%}$ than in the two 7 other conditions during km-3 $(p<0.05$, effect sizes $>0.80)$. Significant higher $\dot{\mathrm{V}}_{\mathrm{E}}$ values in

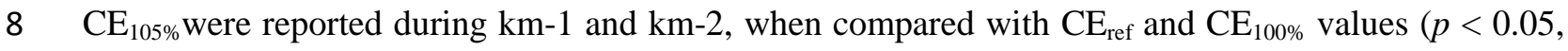

9 effect sizes $<0.50)$, but not during km-3 $(p>0.05)$. No effect of pacing strategy on HR and $\dot{\mathrm{V}}_{\mathrm{E}}$ values was observed when comparing $\mathrm{CE}_{\text {ref }}$ and $\mathrm{CE}_{100 \%}$ at any period of the combined event $(p>0.05)$. No significant effect of pacing strategy was observed on $\left[\mathrm{La}^{-}\right]_{\mathrm{b}}$ values at the end of the combined event $(p$ $=0.29$.

\section{DISCUSSION}

Paragraph 29 The purpose of the present study was to assess the physiological demands associated with the shooting-running event of the modern pentathlon, which will be introduced in the 2012 Olympic Games. To this end, a simulated shooting-running event was performed by elite pentathletes. Secondly, our research examined the physiological responses associated with three different pacing strategies, and observed the effect of these strategies on overall performance. The most important findings were as follows: (i) the completion of the combined event was performed close to $\mathrm{v} \dot{\mathrm{V}} \mathrm{O}_{2 \max }$ and characterized by an increase of running speed over the last kilometre, leading to a maximal aerobic demand and a high anaerobic contribution_(Part 1); (ii) the absence of any significant effect $\underline{\text { of }}$ the start strategy within km-1 and km-2 on the performance parameters (Part 2); (iii) running above $\mathrm{v} \dot{\mathrm{V}} \mathrm{O}_{2 \max }$ over the first two kilometres had no significant effect on overall performance but resulted in a subsequent decrease of performance during the last shooting-running combination (Part 3). 


\section{Part 1: Physiological demand of the combined event}

3 Paragraph 30 All the pentathletes involved in the present study used a positive-split strategy during

4 each kilometre of the international competition, whereby their running speed decreased after an 5 aggressive $170 \mathrm{~m}$ start. In addition, they all ran the last kilometre faster than the first two. The 6 pentathletes succeeded in reproducing this strategy during the $\mathrm{CE}_{\text {ref }}$ condition, which was consistent 7 with the results reported by Le Meur et al. (2010) during the 2009 Budapest World Cup event. As a

8 result, we considered $\dot{\mathrm{V}}_{2}, \dot{\mathrm{V}}_{\mathrm{E}}, \mathrm{HR}$ and $\left[\mathrm{La}^{-}\right]_{\mathrm{b}}$ recorded during $\mathrm{CE}_{\text {ref }}$ as being representative of the 9 metabolic physiological demands associated with the new combined event in high level pentathletes. This assumption was strengthened by the absence of significant difference in overall, running and shooting performances between the international competition and $\mathrm{CE}_{\text {ref. }}$ The observation of elevated values on fractions of $\mathrm{HR}_{\max }(96 \pm 3 \%)$ and $\dot{\mathrm{V}} \mathrm{O}_{2 \max }\left(100 \pm 5 \% \dot{\mathrm{V}} \mathrm{O}_{2 \max }\right)$ indicated that the completion of this new Olympic discipline is highly demanding for the aerobic pathway (Fig. 3). These results confirmed that the run in modern pentathlon is completed in the severe intensity domain (Hill et al. 2002), as suggested by Whyte and James (2007). This finding may explain the high $\dot{\mathrm{V}}_{2 \max }$ values measured in the high level pentathletes engaged in the present study $\left(72 \pm 5 \mathrm{mLO}_{2} \cdot \mathrm{min}^{-1} \cdot \mathrm{kg}^{-1}\right)$, which reflect those already reported in elite biathletes (Rundell and Bacharach 1995), runners (Billat et al. 2001a), and triathletes (Le Meur et al. 2009). Considering the fact that $\mathrm{v} \dot{\mathrm{V}} \mathrm{O}_{2 \max }$ values were significantly lower than the values reported on both elite runners (Billat et al. 2001a) and triathletes (Le Meur et al. 2009) of the same calibre, it is possible that elite pentathletes may demonstrate lower running economy than other endurance athletes. This finding may be attributed to the variety of pentathlon disciplines, which may result in a relative lack of specific training focus for running.

Paragraph 31 Interestingly, the results of the present study were in line with the mean values of 99\% $\mathrm{HR}_{\max }$ and $95 \% \dot{\mathrm{V}} \mathrm{O}_{2 \max }$ measured by Duffield et al. (2005) during a maximal $3000 \mathrm{~m}$ run in trained track athletes (when considering the whole race). $\left[\mathrm{La}^{-}\right]_{\mathrm{b}}$ values at the end of $\mathrm{CE}_{\text {ref }}$ were similar to peak 
1 values reported by Shave et al. (2001) in trained athletes after a maximal $3000 \mathrm{~m}$ run (13.6 \pm 1.5

2 mmol. $\mathrm{L}^{-1}$ in the present study vs. $15.9 \pm 2.1 \mathrm{mmol} . \mathrm{L}^{-1}$ for Shave et al. 2001). Taken together, these

3 results demonstrate that elite pentathletes will benefit from developing comparable physiological

4 abilities to $3000 \mathrm{~m}$ track runners in preparing for the combined event. However, because $\dot{\mathrm{V}} \mathrm{O}_{2}$ values

5 dropped to $65 \%$ of $\dot{\mathrm{V}}_{2 \max }$ after shooting sessions 2 and 3 (results not presented), it is likely that the

6 new combined event may accentuate the necessity to reach $\underline{\dot{\mathrm{V}}} \underline{\mathrm{O}}_{2}$ values near $\underline{\dot{\mathrm{V}}} \underline{\mathrm{O}_{2}} \underline{\max } \underline{\text { in a short delay }}$ (Fig. 3). In addition, it is interesting to note that the increase in running speed over $\mathrm{km}-3$ systematically observed by Le Meur et al. (2010) was clearly confirmed in the present study $(+6.9 \%$ and $+6.0 \%$ between km-2 and km-3 in Le Meur et al. (2010) and in the present study, respectively,

Fig. 2A). Considering that $\dot{\mathrm{V}}_{2}$ values did not increase during the $3^{\text {rd }}$ kilometre (i.e. the subjects had reached $\dot{\mathrm{V}}_{2 \max }$ during $\mathrm{km}-2$, Table 3), it suggests that elite pentathletes may also benefit from improving their anaerobic capacity, so that they may be able to reach speeds above $\mathrm{v} \dot{\mathrm{V}} \mathrm{O}_{2 \max }$ over the last kilometre in order to win or attain better placement on the finish line.

\section{Pacing strategy}

\section{Part 2: Effect of a fast start strategy within the two first kilometres on performance parameters}

17 Paragraph 32 The first hypothesis of the present study was that the positive pacing strategy adopted by the elite pentathletes within the two first kilometres of the international competition investigated in the present study $(+10.8 \%$ over the initial $170 \mathrm{~m}$ of $\mathrm{km}-1$ and $\mathrm{km}-2)$ may have leaded to suboptimal performance. Due to the fact that previous studies have shown that a positive pacing strategy may be 21 associated with early fatigue (Billat et al. 2001b; Hausswirth et al. 2010; Le Meur et al. 2011; Wilberg 22 and Pratt 1988), we suggested that a constant pacing strategy over km-1 and km-2 (associated with potential lower anaerobic contribution at the beginning of the two first kilometres, i.e. $\mathrm{CE}_{100 \%}$ condition) would result in an improved shooting performance and a higher running speed over the last 
1 results did not confirm this hypothesis, while the running speed during $\mathrm{CE}_{\text {ref }}$ was $2.0 \mathrm{~km} \cdot \mathrm{h}^{-1}$ higher over the first $170 \mathrm{~m}$ of km-1 and km-2 than in $\mathrm{CE}_{100 \%}$. Indeed, no significant difference on running speed over km-3,_shooting time_ and overall performance_were reported when comparing $\mathrm{CE}_{\text {ref }}$ and $\underline{\mathrm{CE}}_{100 \%}($ Table 2).

5 Paragraph 33 Interestingly, heart rate, $\dot{\mathrm{V}} \mathrm{O}_{2}$, and $\dot{\mathrm{V}}_{\mathrm{E}}$ responses at the end of the first two kilometres

6 were similar in $\mathrm{CE}_{\text {ref }}$ and $\mathrm{CE}_{100 \%}$, suggesting that the manipulation of the initial running speed did not 7 affect the aerobic response during the run, or at the beginning of each shooting session (Table 3). The 8 absence of $\left[\mathrm{La}^{-}\right]_{\mathrm{b}}$ measurements after each kilometre made it difficult to discuss the evolution of 9 anaerobic contribution during the two conditions. However, no significant differences were reported 10 between $\mathrm{CE}_{\text {ref }}$ and $\mathrm{CE}_{100 \%}$ of the peak value reached after the completion of the combined event, 11 suggesting a relatively similar global glycolytic supply for these two strategies. In the same time, all 12 shooting performance parameters (time, accuracy, and delay per shot) remained stable throughout the 13 combined event only in the $\mathrm{CE}_{\text {ref }}$ condition. Indeed, while both shooting time and shooting accuracy 14 did not reveal any significant variation in $\mathrm{CE}_{100 \%}$, a small increase in the delay per shot was observed 15 during the third shooting sessions (Fig. 2D). Taken together, these results suggested that the fast start 16

Paragraph 34 The second hypothesis of the present study was that the adoption of a higher mean running speed over km-1 and km-2 (i.e. $\mathrm{CE}_{105 \%}$ ) would improve overall running performance, without compromising shooting time, when compared with $\mathrm{CE}_{\text {ref }}$ and $\mathrm{CE}_{100 \%}$. Nevertheless, no significant 22 differences in overall performance or global shooting or running times were reported between $\mathrm{CE}_{105 \%}$ 23 and the two other conditions_(Table 2). While a significant increase in running speed was reported 24 over km-3 for both $\mathrm{CE}_{\text {ref }}$ and $\mathrm{CE}_{100 \%}$, setting running speeds above $\mathrm{v} \dot{\mathrm{V}} \mathrm{O}_{2 \max }$ over the two first 25 kilometres during $\mathrm{CE}_{105 \%}\left(102 \%\right.$ and $101 \% \underline{\mathrm{V}} \dot{\mathrm{V}} \mathrm{O}_{2 \max }$, over $\mathrm{km}-1$ and $\mathrm{km}-2$, respectively) resulted in 
1 global positive pacing for all nine pentathetes, whereby the running speed decreased by $8 \%$ over the

2 last kilometre (-1,5 km.h-1, $+22 \mathrm{~s}$, Fig. 2A). Considering the fact that no significant differences in

3 oxygen consumption was observed between the three conditions during km-1 and km-2, it suggested

4 that the completion of these sections during $\mathrm{CE}_{105 \%}$ was related to i) a faster oxygen kinetic than CEref

5 and $\mathrm{CE}_{100 \%}$; ii) a greater glycolytic contribution; or iii) both. The absence of significant difference in

6 final peak $[\mathrm{La}-]_{\mathrm{b}}$, despite a slower pace over the last kilometre in this condition confirmed that the pentathletes may have increased the mobilization of their anaerobic reserve during the two first kilometres of $\mathrm{CE}_{105 \%}$. This hypothesis may explain i) the slowdown observed over the last kilometre only in this condition and ii) the lower speed reported over each sections of $\mathrm{km}-3$ in $\mathrm{CE}_{105 \%}$ than in the two other conditions. Collected together, these results confirmed that the development of a high anaerobic capacity may represent a factor of performance in the new combined event for elite pentathletes. Besides, a more detailed analysis of the pacing strategy adopted over km-3 revealed a fast $\underline{\text { start coupled with a systematic endspurt (i.e. U-shaped pacing strategy) in all the experimental }}$ conditions. This finding showed that pacing strategy was altered continuously throughout the last kilometre, whatever the strategy employed, possibly in response to changing afferent signals but also

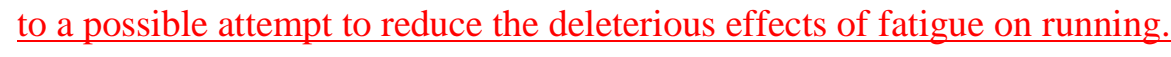

Paragraph 35 No significant differences were reported between the three conditions for the shooting performance. However, the results revealed a tendency of $\mathrm{CE}_{105 \%}$ to reveal a weaker performance, when compared to $\mathrm{CE}_{\text {ref }}$ and $\mathrm{CE}_{100 \%}(p=0.11)$ and a significant increase in shooting time during the third shooting session was observed only for $\mathrm{CE}_{105 \%}(+12 \mathrm{~s},+25 \%)$, suggesting that $\mathrm{CE}_{105 \%}$ may be more stressful for pentathletes during the last shooting session (Fig. 2B). This decrease in shooting performance was explained by a significant increase in the delay per shot and a non significant tendency of shooting accuracy to decrease during the same period $(p=0.07)$ (Fig. 2C, D). This finding was consistent with the reverse U-shape relationship classically reported in the literature when considering the reciprocal influence of physical exercise level and psycho cognitive process (Brisswalter et al. 2002). Even the present results should be taken with caution considering the absence of systematic statistical significant differences in overall and shooting performances, they 
suggested that the higher energy expenditure associated with $\mathrm{CE}_{105 \%}$ during km-1 and km-2 may have been deleterious for the visual and/or psychosensorial mechanisms involved by the shooting task. Despite it was already verified in elite biathletes (Hoffman et al. 1992), this hypothesis required further investigations in the context of high-level modern pentathlon.

Paragraph 36 In conclusion, the physiological demands of the new combined shooting-running event

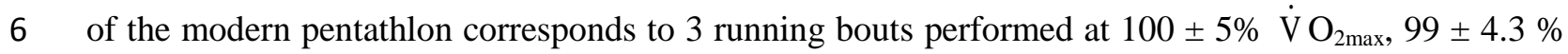
$7 \quad \mathrm{v} \dot{\mathrm{V}} \mathrm{O}_{2 \max }$ and $96 \pm 3 \% \mathrm{HR}_{\max }$, interspersed by a transitional shooting period of almost $35 \mathrm{sec}$. In this 8 context, and considering the high values of $\dot{\mathrm{V}} \mathrm{O}_{2 \max }$ of this elite population $\left(72.5 \mathrm{mlO}_{2} \cdot \mathrm{min}^{-1} \cdot \mathrm{kg}^{-1}\right)$, this 9 first analysis of the new combined event suggests that the energy demand is very high and mainly supplied by aerobic metabolism. The participation of the anaerobic pathway does not seem to be negligible considering that both the spontaneous high running pace over the last $1 \mathrm{~km}$ section (103\% $\mathrm{v} \dot{\mathrm{V}} \mathrm{O}_{2 \max }$ ), and the high peak $\left[\mathrm{La}^{-}\right]_{\mathrm{b}}$ values reached at the end of the combined event. Additionally, the present results revealed that minor differences in mean running speeds imposed over the first two first kilometres between $\mathrm{CE}_{\text {ref }}$ and $\mathrm{CE}_{105 \%}\left(\sim 0.6 \mathrm{~km} \cdot \mathrm{h}^{-1}\right)$ greatly influence the pacing adopted during the event as a whole by modifying the global strategy (negative vs. positive pacing) without influencing overall performance. Since each failed shot takes approximately $6 \mathrm{sec}$ to make-up over a 1-km section $\left(+0.6 \mathrm{~km} \cdot \mathrm{h}^{-1}\right.$ in the range of speeds observed in international modern pentathlon competitions), improving the intrinsic shooting performance level, and the ability to shoot under both pressure and fatigue, may constitute the best way to optimize the performance level of elite pentathletes in the new combined event in the short term (in the perspective of 2012 London Olympic Games). This assumption is consistent with the results reported by Le Meur et al. (2010), which showed that clear rounds were scarce during a World Cup competition, and the best performers in the combined event distinguished themselves due to their greater shooting performance. Elite pentathletes should consider these findings for planning their physical training programs, notably in the perspective of the 2012 London Olympic Games. 


\section{Acknowledgments}

1

3

4

5 6

7

2 This study was made possible by technical support from the French Ministry of Sport and the French

3 Federation of Modern Pentathlon. The authors are especially grateful to the athletes for their help and 4 cooperation. 
Abbiss CR, Laursen PB (2008) Describing and understanding pacing strategies during athletic competition. Sports Med 38: 239-252

Aisbett B, Le Rossignol P, McConell GK, Abbiss CR, Snow R (2009) Effects of starting strategy on 5-min cycling time-trial performance. J Sports Sci 27: 1201-1209

Bailey SJ, Vanhatalo A, DiMenna FJ, Wilkerson DP, Jones AM (2011) Fast-start strategy improves VO2 kinetics and high-intensity exercise performance. Med Sci Sports Exerc 43: 457-467

Billat VL, Demarle A, Slawinski J, Paiva M, Koralsztein JP (2001a) Physical and training characteristics of top-class marathon runners. Med Sci Sports Exerc 33: 2089-2097

Billat VL, Slawinski J, Danel M, Koralsztein JP (2001b) Effect of free versus constant pace on performance and oxygen kinetics in running. Med Sci Sports Exerc 33: 2082-2088

Bishop D, Bonetti D, Dawson B (2002) The influence of pacing strategy on VO2 and supramaximal kayak performance. Med Sci Sports Exerc 34: 1041-1047

Brisswalter J, Collardeau M, Rene A (2002) Effects of acute physical exercise characteristics on cognitive performance. Sports Med 32: 555-566

Cheng B, Kuipers H, Snyder AC, Keizer HA, Jeukendrup A, Hesselink M (1992) A new approach for the determination of ventilatory and lactate thresholds. Int J Sports Med 13: 518-522

Cohen J (ed) (1988) Statistical power analysis for the behavioral sciences. NJ: Lawrence Erlbaum, Hillsdale

Duffield R, Dawson B, Goodman C (2005) Energy system contribution to 1500- and 3000-metre track running. J Sports Sci 23: 993-1002

Hausswirth C, Le Meur Y, Bieuzen F, Brisswalter J, Bernard T (2010) Pacing strategy during the initial phase of the run in triathlon: influence on overall performance. Eur J Appl Physiol 108: 1115-1123

Hill DW, Poole DC, Smith JC (2002) The relationship between power and the time to achieve .VO(2max). Med Sci Sports Exerc 34: 709-714

Hoffman MD, Gilson PM, Westenburg TM, Spencer WA (1992) Biathlon shooting performance after exercise of different intensities. Int J Sports Med 13: 270-273

Howley ET, Bassett DR, Jr., Welch HG (1995) Criteria for maximal oxygen uptake: review and commentary. Med Sci Sports Exerc 27: 1292-1301

Le Meur Y, Bernard T, Dorel S, Abbiss CR, Honnorat G, Brisswalter J, Hausswirth C (2011) Relationships between triathlon performance and pacing strategy during the run in an international event. Int J Sports Physiol Perform 6: 183-194

Le Meur Y, Hausswirth C, Abbiss C, Baup Y, Dorel S (2010) Performance factors in the new combined event of modern pentathlon. J Sports Sci 28: 1111-1116

Le Meur Y, Hausswirth C, Dorel S, Bignet F, Brisswalter J, Bernard T (2009) Influence of gender on pacing adopted by elite triathletes during a competition. Eur J Appl Physiol 106: 535-545

Pyne DB, Boston T, Martin DT, Logan A (2000) Evaluation of the Lactate Pro blood lactate analyser. Eur J Appl Physiol 82: 112-116

Rundell KW, Bacharach DW (1995) Physiological characteristics and performance of top U.S. biathletes. Med Sci Sports Exerc 27: 1302-1310

Shave R, Whyte G, Siemann A, Doggart L (2001) The effects of sodium citrate ingestion on 3,000meter time-trial performance. J Strength Cond Res 15: 230-234

Thompson KG, MacLaren DP, Lees A, Atkinson G (2003) The effect of even, positive and negative pacing on metabolic, kinematic and temporal variables during breaststroke swimming. Eur J Appl Physiol 88: 438-443

UIPM database, http://www.pentathlon.org/results/competition-results

Whyte GP, James DV (2007) Modern Pentathlon. In: Routledge (ed) Sport and Exercise Physiology Testing Guidelines: The Bristish Association of Sport and Exercise Sciences Guide. Taylor \& Francis, New York, pp. 165-172 
1 Wilberg RB, Pratt J (1988) A survey of the race profiles of cyclists in the pursuit and kilo track events.

12 Can J Sport Sci 13: 208-213

23

34

4

5

6

7

8

9

10

11

12

13

14

15

16

17

18

19

20

21

22

23

24

25

26

27

28

29

30

31

32

33

34

35

36

37

38

39

40

41

42

43

44

45

46

47

48

49

50

51

52

53

54

55

56

57

58

59

60

61

62

63

64

65 


\section{1} the international competition. Km-3 was always self-paced. Grey portions: $\dot{\mathrm{V}}_{2}, \dot{\mathrm{V}}_{\mathrm{E}}, \mathrm{HR}$ interval 8 measurements; dark drops: blood samples. RS: running section, SS: shooting session.

9 10 11 12 13 14 15 FIGURE 3. Example of $\mathrm{HR}$ (grey line) and $\dot{\mathrm{V}} \mathrm{O}_{2}$ (black line) evolutions during the reference 16 combined event for one male pentathlete. Dashed lines represent maximal values reached during the 17 maximal incremental running test. 


\section{International competition}

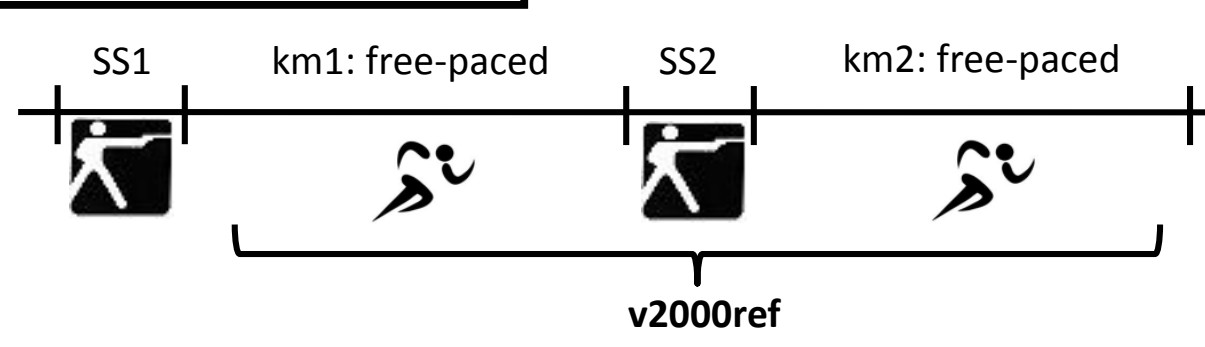

\section{Experimental conditions}

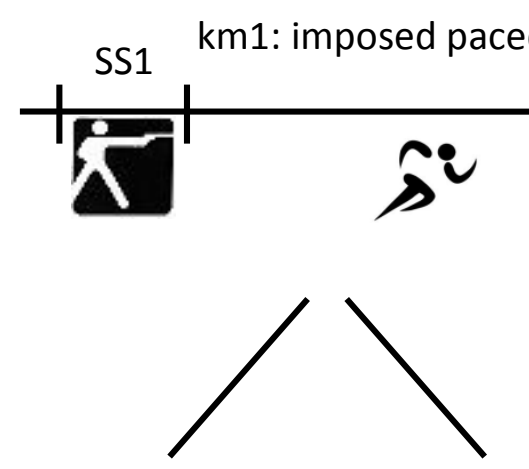

\%v2000ref

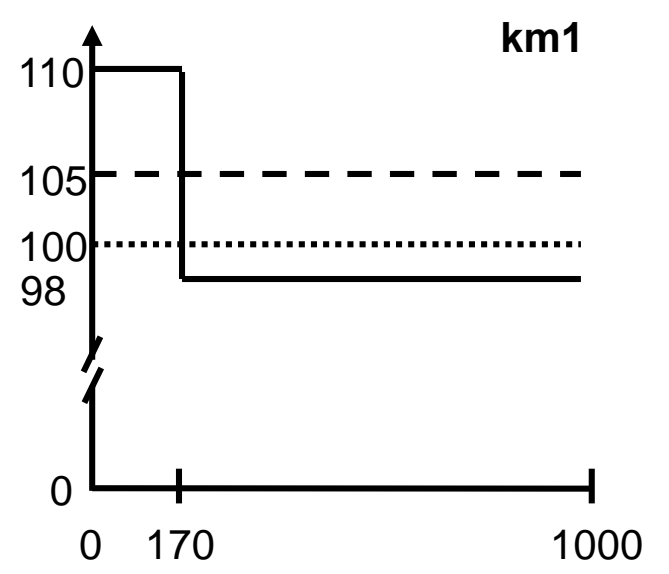

km2: imposed paced* ss3 km3: free-paced

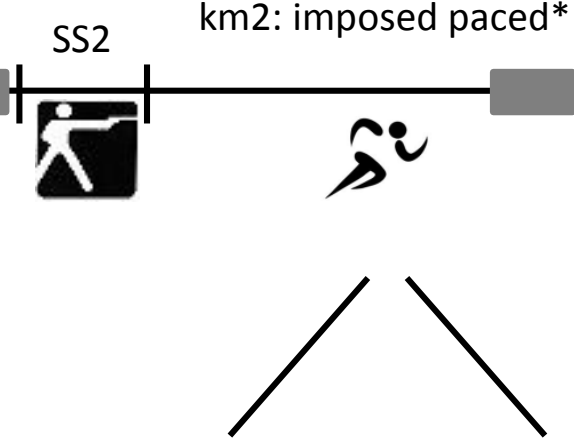

\%v2000ref

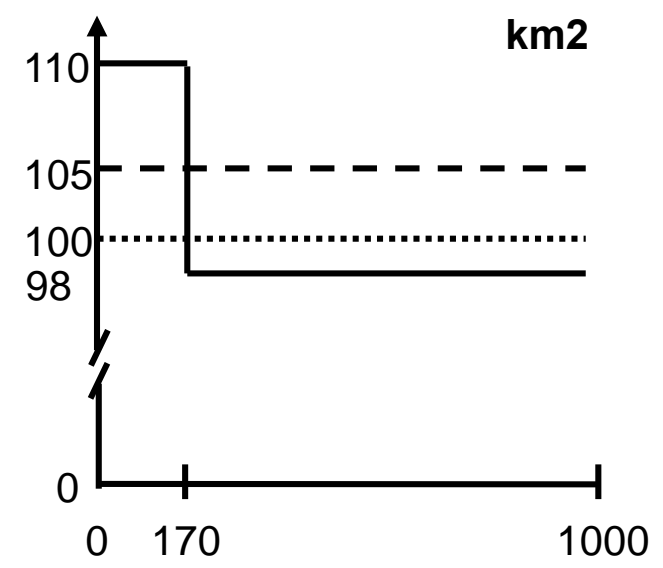

Overall performance Shooting

performance (time, accuracy, delay per shot)

Running time $\mathrm{HR}, \mathrm{VO}_{2}, \mathrm{~V}_{\mathrm{E}},\left[\mathrm{La}^{-}\right]$

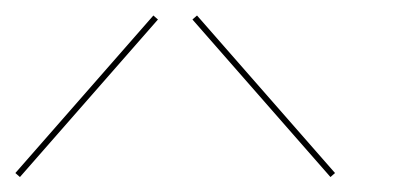

\%v2000ref

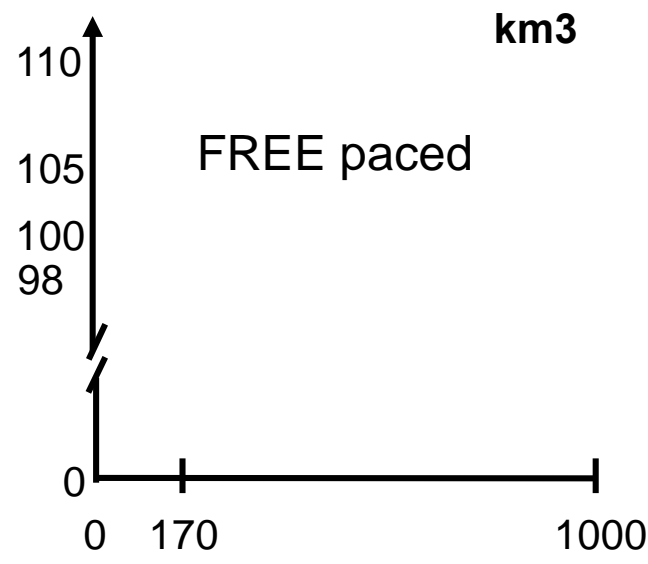


Figure 2

A.

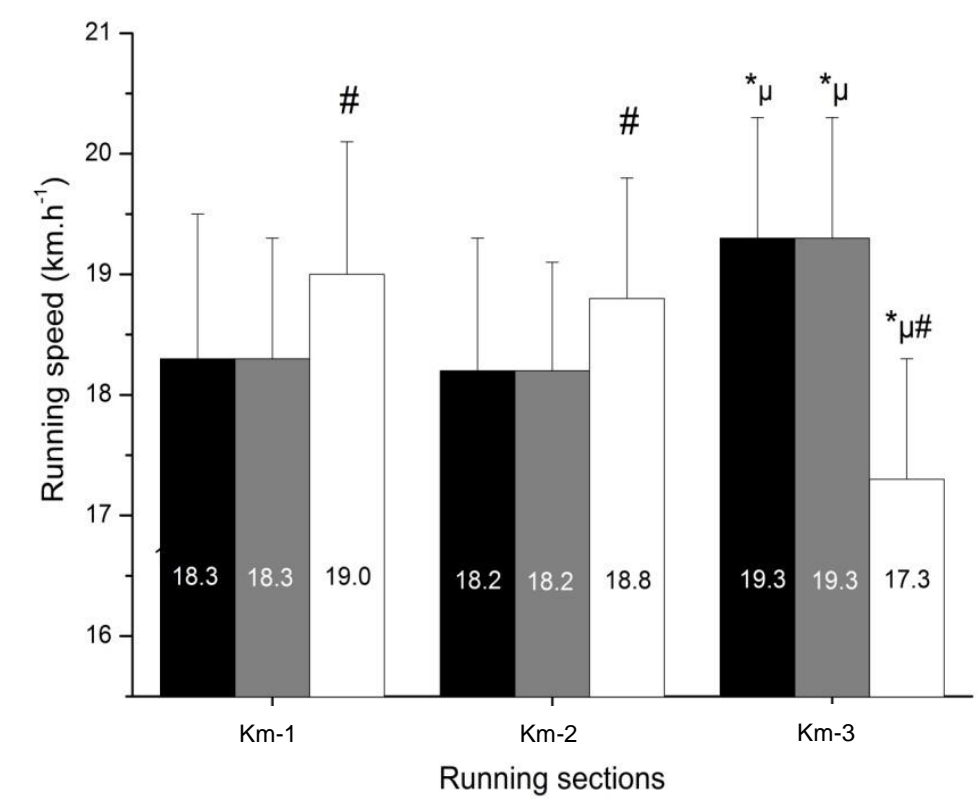

C.

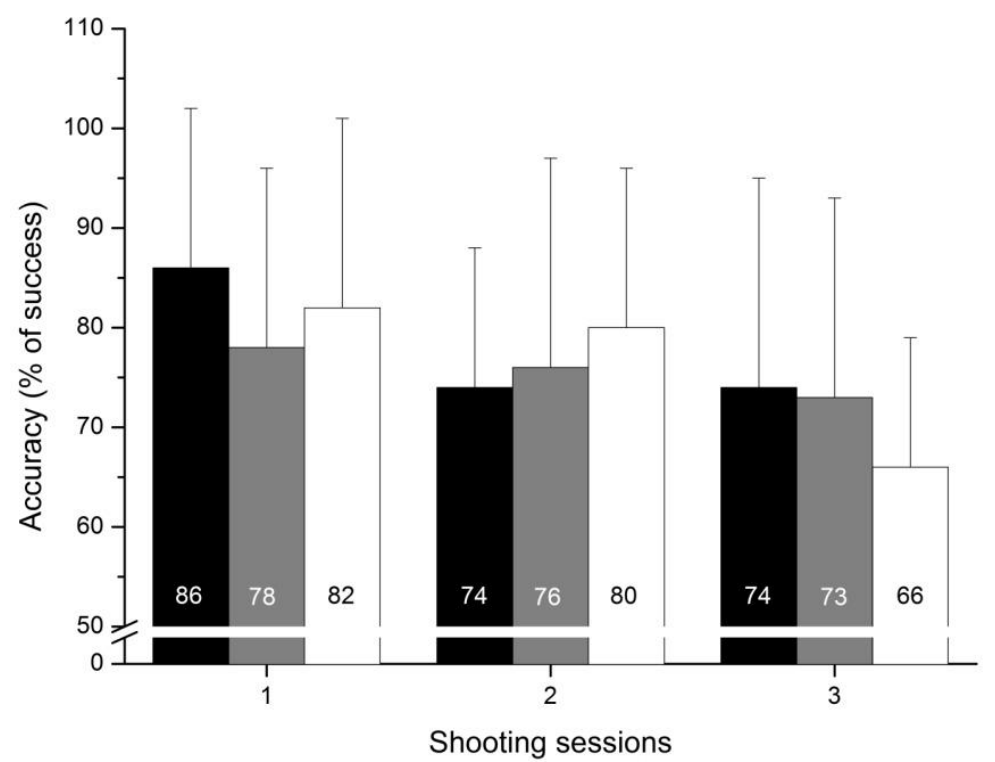

B.

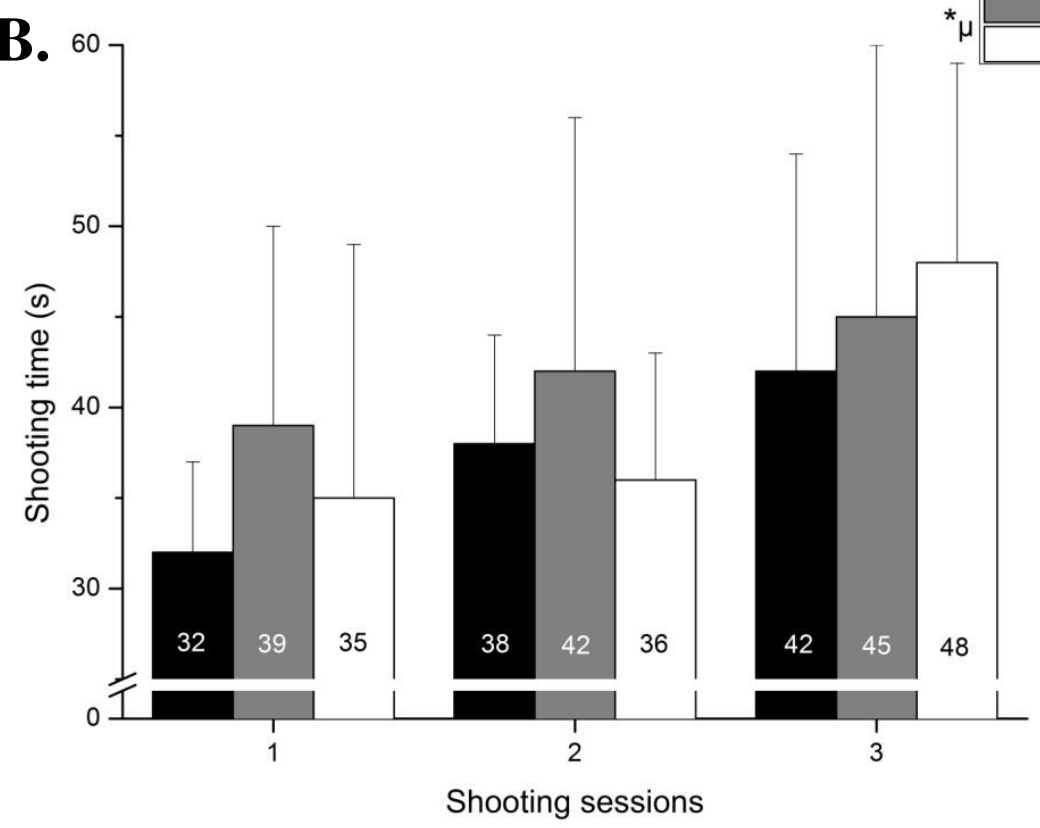

D.

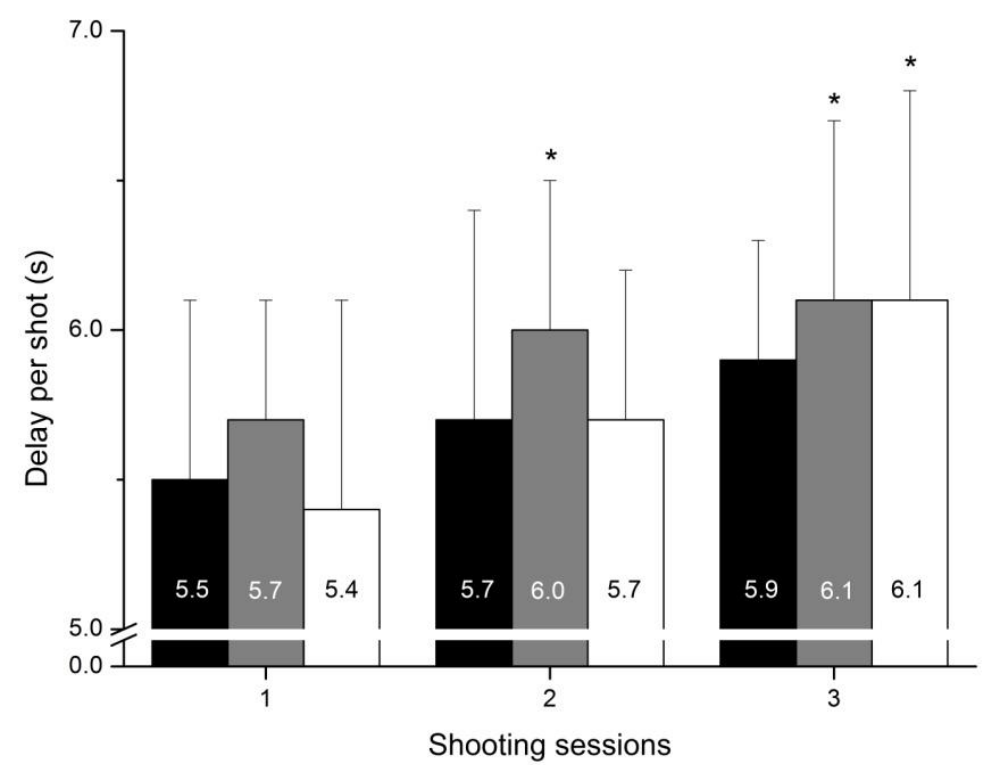




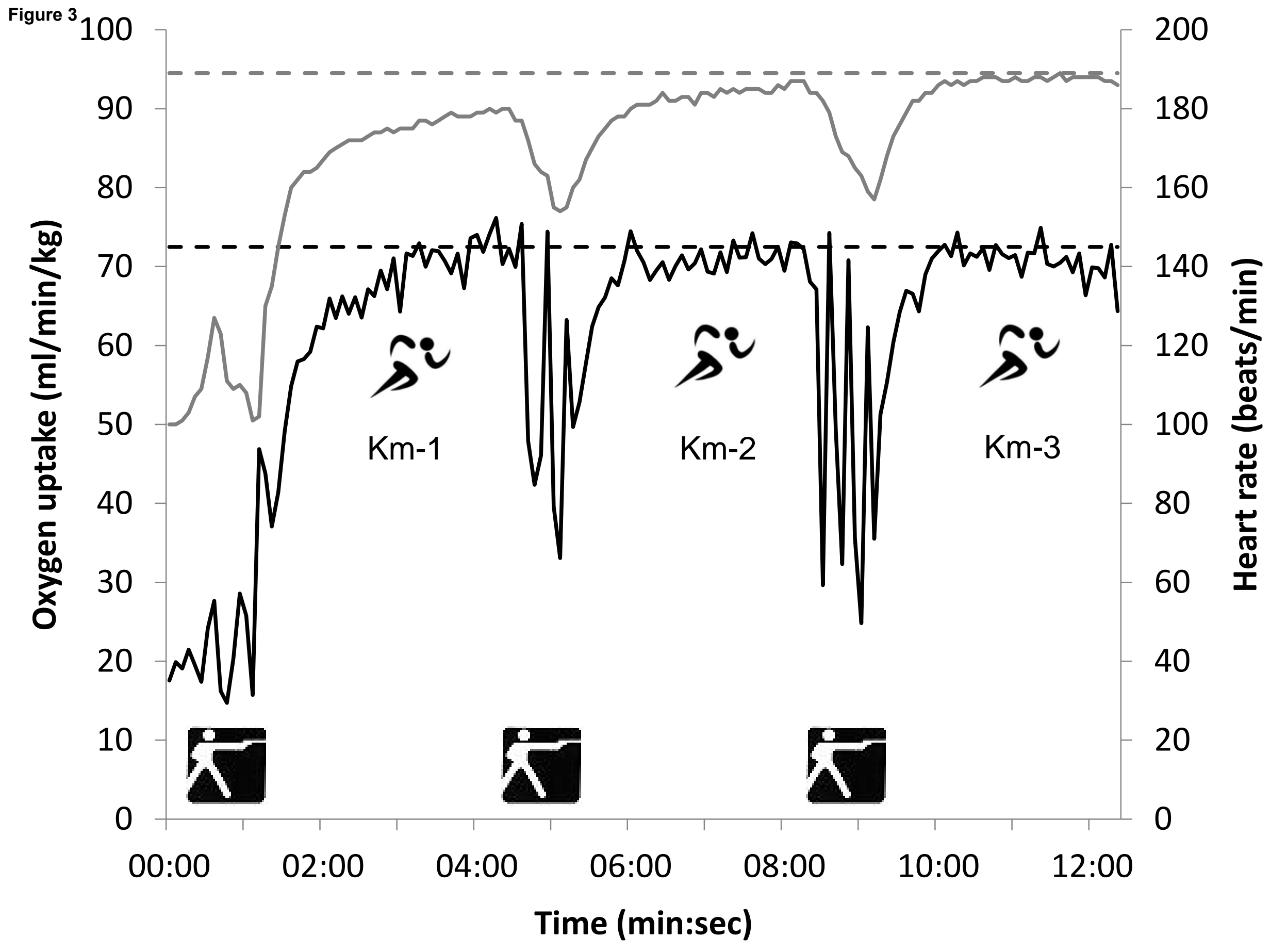




$$
\text { Men }(n=8) \quad \text { Women }(n=1)
$$

\begin{tabular}{lcc}
\hline Age (years) & $20 \pm 3$ & 20 \\
\hline Height $(\mathrm{cm})$ & $181 \pm 4$ & 174 \\
\hline Weight $(\mathrm{kg})$ & $74 \pm 6$ & 59 \\
\hline$\dot{\mathrm{V}} \mathrm{O}_{2 \max }\left(\mathrm{mL} \cdot \mathrm{min}^{-1} \cdot \mathrm{kg}^{-1}\right)$ & $74 \pm 5$ & 108 \\
\hline$\dot{\mathrm{V}}_{\mathrm{Emax}}\left(\mathrm{L} \cdot \mathrm{min}^{-1}\right)$ & $170 \pm 15$ & 186 \\
\hline $\mathrm{HR}_{\max }\left(\mathrm{beats}_{\mathrm{min}}{ }^{-1}\right)$ & $197 \pm 5$ & 17,0 \\
\hline $\mathrm{V}_{\max }\left(\mathrm{km} \cdot \mathrm{h}^{-1}\right)$ & $19,6 \pm 1,0$ & 17,0 \\
\hline$\dot{\mathrm{V}} \mathrm{O}_{2 \mathrm{max}}\left(\mathrm{km} \cdot \mathrm{h}^{-1}\right)$ & $18,9 \pm 0,5$ & 14,0 \\
\hline $\mathrm{V}_{\mathrm{LT}}\left(\mathrm{km} \cdot \mathrm{h}^{-1}\right)$ & $16,6 \pm 0,9$ & 90,5 \\
\hline $\mathrm{V}_{\mathrm{LT}}\left(\% \dot{\mathrm{V}}_{2 \max }\right)$ & $93,0 \pm 2,1$ & \\
\hline
\end{tabular}

TABLE 1. Characteristics of the subjects participating in the present study $(n=9)$. Values are expressed as mean $\pm \mathrm{SD}$.

$\dot{\mathrm{V}} \mathrm{O}_{2 \max }$, maximal oxygen uptake; $\dot{\mathrm{V}}_{\mathrm{Emax}}$, maximal minute ventilation; $\mathrm{HR}_{\max }$ : maximal heart rate; $\mathrm{v} \dot{\mathrm{V}} \mathrm{O}_{2 \max }$, velocity associated with $\dot{\mathrm{V}} \mathrm{O}_{2 \max }$. 


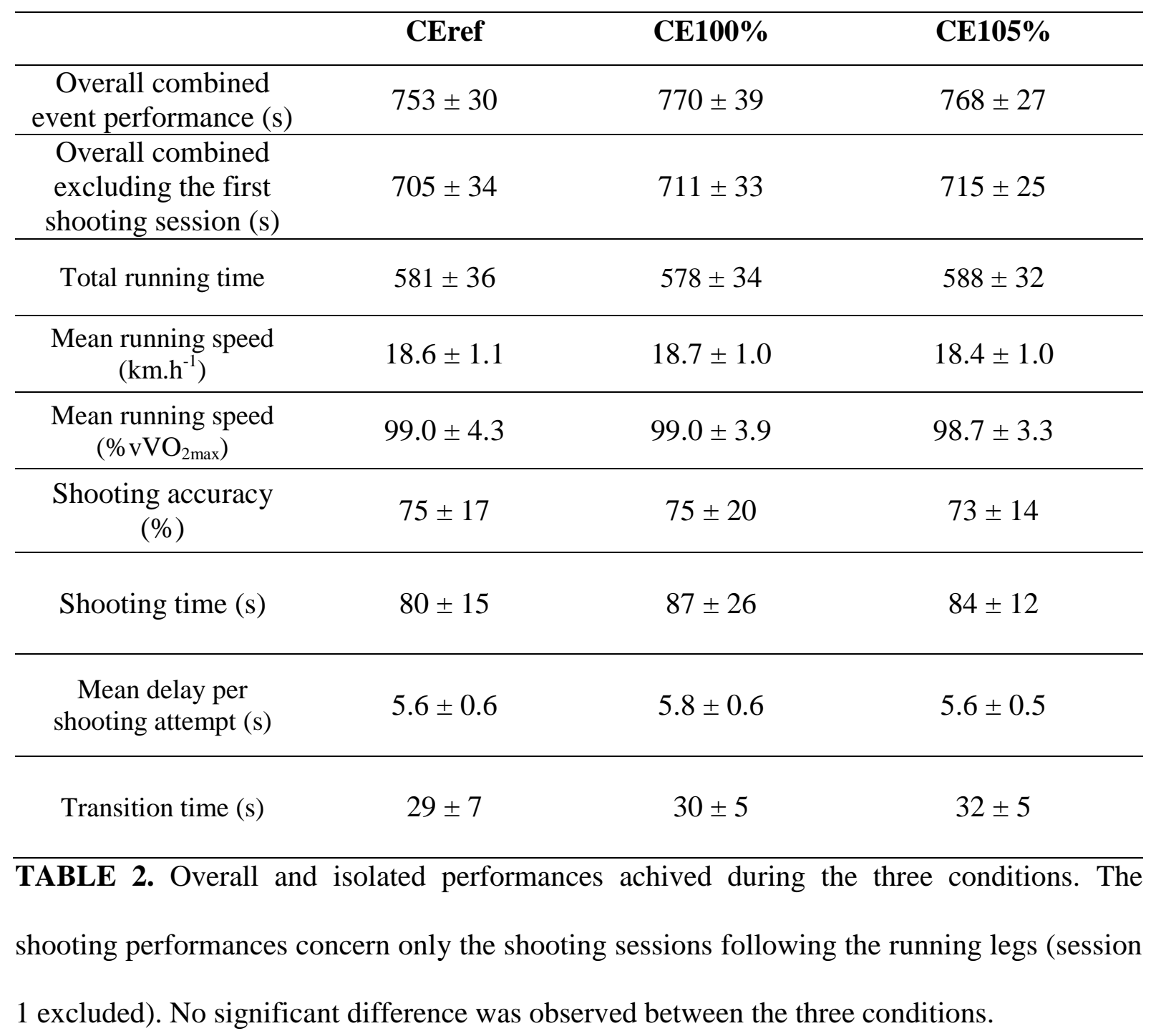




Parameters $\quad$ Oxygen uptake $\left(\mathrm{V}_{2}\right)\left(\mathrm{mL} \cdot \mathrm{min}^{-1} \cdot \mathrm{kg}^{-1}\right) \quad$ Expiratory flow $\left(\dot{\mathrm{V}}_{\mathrm{E}}\right)\left({\left.\mathrm{L} \cdot \mathrm{min}^{-1}\right)}_{\left(\left[\mathrm{La}^{-1}\right]_{\mathrm{b}}\right)\left(\mathrm{mmol}_{\mathrm{L}} \mathrm{L}^{-1}\right)}\right.$

\begin{tabular}{ccccccccccc}
\hline Sections & $\mathrm{Km}-1$ & $\mathrm{Km}-2$ & $\mathrm{Km}-3$ & $\mathrm{Km}-1$ & $\mathrm{Km}-2$ & $\mathrm{Km}-3$ & $\mathrm{Km}-1$ & $\mathrm{Km}-2$ & $\mathrm{Km}-3$ & $\mathrm{Maximal}$ value \\
\hline $\mathrm{CE}_{\text {ref }}$ & $73.1 \pm 3.7$ & $73.1 \pm 5.0$ & $71.0 \pm 5.8$ & $153 \pm 19$ & $166 \pm 16^{*}$ & $177 \pm 25^{*}$ & $182 \pm 4$ & $189 \pm 6^{*}$ & $195 \pm 7^{*}$ & $13.6 \pm 1.5$ \\
\hline $\mathrm{CE}_{100 \%}$ & $71.4 \pm 4.1$ & $72.4 \pm 4.1$ & $72.0 \pm 5.2$ & $152 \pm 16$ & $162 \pm 15^{*}$ & $182 \pm 22^{*}$ & $183 \pm 5$ & $189 \pm 6^{*}$ & $194 \pm 7^{*}$ & $13.7 \pm 1.2$ \\
\hline $\mathrm{CE}_{105 \%}$ & $73.7 \pm 5.3$ & $72.5 \pm 5.4$ & $70.5 \pm 6.1$ & $162 \pm 22^{\#}$ & $176 \pm 24^{* \#}$ & $176 \pm 27$ & $185 \pm 8$ & $189 \pm 7^{*}$ & $190 \pm 8^{\#}$ & $13.5 \pm 1.5$ \\
\hline
\end{tabular}

*Significantly different from the previous section, $p<0.05$.

\# Significantly different from $\mathrm{CE}_{\mathrm{ref}}$ and $\mathrm{CE}_{100 \%}, p<0.05$.

TABLE 3. Group mean ( \pm SD) values for oxygen uptake, expiratory flow, heart rate and blood lactate obtained during the running legs of the three combined events. All the measures were realised during the last 30s of each kilometre. 